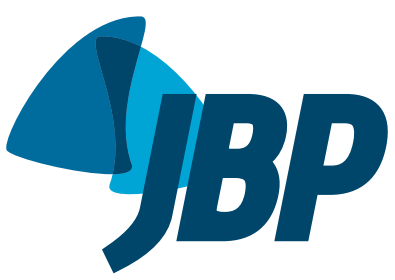

\section{Measuring slow vital capacity to detect airflow limitation in a woman with dyspnea and a preserved $\mathrm{FEV}_{1} / \mathrm{FVC}$ ratio}

\author{
Danilo Cortozi Berton ${ }^{1, a}$, José Alberto Neder ${ }^{2, b}$
}

\section{THE CLINICAL SCENARIO}

A 42-year-old woman with a body mass index (BMI) of $51.2 \mathrm{~kg} / \mathrm{m}^{2}$ was referred to the respiratory clinic for investigation of progressive breathlessness which had worsened in the past 5 years-her score on the modified Medical Research Council scale at presentation was 3 (i.e., she reported having to stop for breath after walking for only a few minutes). She was a never smoker, and her dyspnea had been mainly attributed to obesity.

\section{THE UNDERLYING PHYSIOLOGY}

Spirometry showed a mild-to-moderate, proportional reduction in $\mathrm{FEV}_{1}$ and in $\mathrm{FVC}$, which resulted in a preserved $\mathrm{FEV}_{1} / \mathrm{FVC}$ ratio (Figure $1 \mathrm{~A}$ ). According to the latest American Thoracic Society/European Respiratory Society algorithm for the interpretation of pulmonary function tests, the decision to label this pattern as restrictive or obstructive depends on measurements of TLC. ${ }^{(1)}$ The authors of that document also stated that, although FVC is often used in the abovementioned ratio, it is preferable to use the largest available VC, whether it is that obtained during inspiration, that obtained during slow expiration, or that obtained during forced expiration. However, the FVC may underestimate the "true" maximal VC due to early closure of the small airways at low lung volumes. That is especially true in the presence of increased small airway compressibility or collapsibility. ${ }^{(2)}$ It follows that a "pseudo-normal" $\mathrm{FEV}_{1} / \mathrm{FVC}$ ratio might occur in patients with obstructive ventilatory disorder, provided there is a large difference between the slow vital capacity (SVC) and the FVC. Nevertheless, there are few reference values for SVC. It is possible that FVC decreases with aging at a faster rate than does SVC(3); that is, a low $\mathrm{FEV}_{1} / \mathrm{SVC}$ ratio might simply reflect the physiological effects of senescence. Therefore, there are potential advantages and disadvantages to using SVC rather than FVC in the $\mathrm{FEV}_{1} / \mathrm{VC}$ ratio. A large recent study analyzing 13,893 consecutive adults with preserved $\mathrm{FEV}_{1} / \mathrm{FVC}$ ratios and TLCs shed new light on this controversial issue. ${ }^{(4)}$ The authors reported the following: one in every five subjects presented with a low $\mathrm{FEV}_{1} / \mathrm{SVC}$ ratio ("discordant" subjects); most subjects showing obstruction only according to the $\mathrm{FEV}_{1} / \mathrm{SVC}$ ratio were highly likely to have airway disease and dysfunction according to a cluster of clinical and physiological variables; regardless of the gender of the subject, the variables age $<60$ years, $\mathrm{BMI}>30 \mathrm{~kg} / \mathrm{m}^{2}$, and $\mathrm{FEV}_{1}>70 \%$ of the predicted value were all associated with "discordance"; and "discordant" subjects $\geq 70$ years of age showed no other evidence of airway disease or dysfunction.

\section{OVERVIEW}

Due to time and operational constraints, most pulmonary function testing laboratories in primary care still perform only the forced expiratory maneuver. ${ }^{(5)}$ Given the results of the abovementioned study ${ }^{(4)}$ adding the SVC maneuver may represent a simple strategy to reveal an obstructive ventilatory defect that was missed by determination of the $\mathrm{FEV}_{1} / \mathrm{FVC}$ ratio in a non-elderly ( $<60$ year-old) obese subject with a high pre-test probability of airway disease. A positive flow or volume response to inhaled bronchodilator administration might also prove useful to reveal airflow limitation in these subjects. Considering the risk of overdiagnosis of obstruction in the elderly (individuals $>70$ years of age), it seems prudent to avoid using SVC in the $\mathrm{FEV}_{1} / \mathrm{VC}$ ratio in this subpopulation. A case-by-case approach should be applied in subjects 60-70 years of age.

\begin{tabular}{lccccc} 
A & Pre BD & LLN & ULN & Z score & $\%$ pred \\
\hline FVC (L) & 1.95 & 2.55 & 3.83 & -1.94 & 61 \\
FEV $_{1}(\mathrm{~L})$ & 1.51 & 2.05 & 3.27 & -1.89 & 57 \\
FEV $_{1} /$ FVC & 77.54 & 74.66 & 91.66 & -0.66 & 93 \\
\hline & & & & & \\
\hline & & & & & \\
\hline B & Pre BD & LLN & ULN & Z score & $\%$ pred \\
Slow VC (L) & 2.50 & 2.55 & 3.83 & -1.08 & 78 \\
FEV $/$ Slow VC & 60.38 & & & & \\
\hline
\end{tabular}

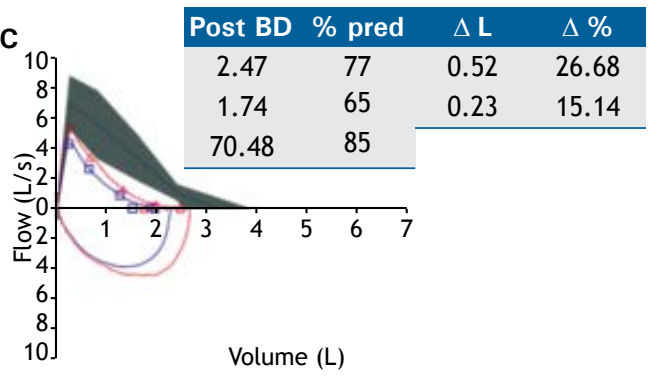

Figure 1. Baseline FVC (panel A) and SVC (panel B). Flow-volume loops before and after acute administration of albuterol (blue and red lines, respectively) are shown in panel $C$, as are the post-bronchodilator values and variations $(\Delta)$ in relation to the baseline values. BD: bronchodilator; LLN: lower limit of normality; ULN: upper limit of normality; and \% pred: percentage of the predicted value. 


\section{OUTCOME}

In the case presented here, involving a middle-aged obese woman with a preserved $\mathrm{FEV}_{1} / \mathrm{FVC}$ ratio (Figure $1 \mathrm{~A})$, airflow limitation was detected on the basis of the SVC (Figure 1B). A positive volume response to inhaled albuterol further supported the diagnosis of an obstructive ventilatory defect (Figure 1C). In fact, the patient reported a noticeable improvement in her shortness of breath after starting twice-daily treatment with inhaled formoterol plus budesonide.

\section{REFERENCES}

1. Pellegrino R, Viegi G, Brusasco V, Crapo RO, Burgos F, Casaburi R, et al. Interpretative strategies for lung function tests. Eur Respir $\mathrm{J}$. 2005;26(5):948-68. https://doi.org/10.1183/09031936.05.00035205

2. Brusasco V, Pellegrino R, Rodarte JR. Vital capacities in acute and chronic airway obstruction: dependence on flow and volume histories. Eur Respir J. 1997;10(6):1316-20. https://doi.org/10.1183/ 09031936.97.10061316

3. Marsh $S$, Aldington $S$, Williams $M$, Weatherall $M$, Shirtcliffe $P$ McNaughton $A$, et al. Complete reference ranges for pulmonary function tests from a single New Zealand population. N Z Med J.
2006;119(1244):U2281

4. Saint-Pierre M, Ladha J, Berton DC, Reimao G, Castelli G, Marillier M, et al. Is the Slow Vital Capacity Clinically Useful to Uncover Airflow Limitation in Subjects With Preserved FEV1/FVC Ratio? Chest. 2019 pii: S0012-3692(19)30143-6.

5. Ferguson GT, Enright PL, Buist AS, Higgins MW. Office spirometry for lung health assessment in adults: A consensus statement from the National Lung Health Education Program. Chest. 2000;117(4):114661. https://doi.org/10.1378/chest.117.4.1146 